\section{Acute Mesenteric Tuberculous Lymphadenitis: A Comparative Analysis of Twenty-one Cases}

Asif Mehmood, Amna Ehsan, Maryam Mukhtar, Faisal Inayat, Waqas Ullah

1.

Corresponding author: Asif Mehmood,drmehmood33@gmail.com

\section{Abstract}

Tuberculosis (TB) remains a major public health concern. Atypical extrapulmonary presentations of this infection may significantly delay its diagnosis and management. Tuberculous lymphadenitis (TL) is an extrapulmonary manifestation of a Mycobacterium tuberculosis infection. It is characterized by necrotizing mycobacterial infection of the lymph nodes. The clinical presentation of this disease ranges from fever and malaise to cervical lymphadenopathy and fistula formation. Herein, we present a comprehensive review of the previously reported cases of mesenteric lymphadenitis. The purpose of this study is to acquaint physicians to identify this disease in a timely manner. Furthermore, this review also highlights the rare presentation and management of TL.

Categories: Internal Medicine, Gastroenterology, Infectious Disease

Keywords: tuberculosis, tuberculous lymphadenitis, mesenteric lymphadenitis

\section{Introduction And Background}

Tuberculosis (TB) is one of the oldest diseases known to affect humans. It has been described in Chinese texts from as long as 2,300 years ago with the evidence of Pott's disease noted in Egyptian mummies [1-2]. Mycobacterium tuberculosis deoxyribonucleic acid (DNA) has also been recovered in Peruvian mummies. Extrapulmonary TB most commonly presents in the form of tuberculous lymphadenitis (TL), which is a local manifestation of this disease [3]. Individuals may present with malaise, low-grade fever, weight loss, cervical lymphadenopathy or fistula formation. Diagnosis can be established using fine-needle aspiration cytology (FNAC) and a core biopsy. Pathologic examination of the biopsy specimens demonstrates granulomatous features typical of TB. We present a comprehensive literature review of previously reported cases of mesenteric lymphadenitis as an extrapulmonary manifestation of TB.

\section{Review}

TB is one of the biggest health challenges in the world. The risk of this infection is greater in crowded populations and it is particularly prevalent in the lower socioeconomic setting. It is the most common diagnosis for cervical lymph node enlargement in developing countries [4]. According to one estimate, approximately 2.2 million people acquire TB every year in India, out of which 0.87 million cases are infective and are responsible for infecting further individuals and spread of the bacterium [5].

TL is the most common manifestation of extrapulmonary TB in human immunodeficiency virus (HIV)-seronegative and HIV-positive individuals. Other common extrapulmonary manifestations of TB include symptoms related to pleura/pericardium, genitourinary system, 


\section{Cureus}

Pott's disease, etc. TL makes up about 35\% of extrapulmonary TB. Mohapatra et al. showed that it has a female predominance and also has a higher prevalence in HIV-infected individuals [6]. TL is a local manifestation of a systemic disease that can occur as a primary disease, reactivation, or direct extension from a contiguous disease focus. It typically presents as scrofula-cervical lymphadenopathy, fistula formation, and typical constitutional symptoms, especially low-grade fevers and weight loss. Travel history is important for the diagnosis of TL as many individuals travel to and from endemic areas of TB and some remain asymptomatic.

We conducted an extensive literature search that retrieved 21 articles. After reading the titles for relevance, 18 articles were excluded, one article did not have enough data, and a total of two articles were selected. One out of these two selected articles reported 20 patients. Therefore, a total of 21 patients with TL were included in this review. All patients of TL were females with a mean age of 43 years (range: 23-69 years). Abdominal distension was the most common presenting feature $(57 \%, \mathrm{n}=12)$, while $52 \%$ of patients presented with abdominal pain. Fever was present in 19\% of individuals (four cases) while dyspnea was present in $9 \%$ individuals (two cases). Other presenting complaints included constipation, menorrhagia, and peritonitis (one case each). About $52 \%$ of patients had primary peritoneal carcinoma (PPC) along with tuberculosis, while ovarian tumor was present in two cases each. Only one case reported ulcerative colitis as a comorbid condition. All individuals with TL had a computed tomography (CT) scan done in their diagnostic work-up $(100 \%, \mathrm{n}=21)$.

All patients with TL were treated surgically, in which peritoneal biopsy was most commonly used $(47 \%, n=10)$. Laparotomy was performed in $38 \%$ of patients $(n=8)$ while $19 \%$ of individuals had bilateral salpingo-oophorectomy and omental biopsy was done (four cases each). Only $9 \%$ cases had a total abdominal hysterectomy performed during surgery (two cases each) while omentectomy, mesenteric biopsy, unilateral salpingo-oophorectomy, adhesiolysis and biopsy, salpingectomy, mass excision, pulmonary nodule resection, and lobectomy were done in one case each. Out of the 21 cases, $95 \%$ of patients had a satisfactory outcome with relapse of TB reported in only one individual [7-8]. The characteristics of these patients are shown in Table 1.

\begin{tabular}{|c|c|c|c|c|c|c|c|}
\hline $\begin{array}{l}\text { S. } \\
\text { No }\end{array}$ & Author & Age/Sex & Presentation & Comorbids & Investigations & Treatment & Outcome \\
\hline 1 & $\begin{array}{l}\text { Kraft } A \text { et } \\
\text { al. [7] }\end{array}$ & $46 / \mathrm{F}$ & N/A & $\begin{array}{l}\text { Ulcerative } \\
\text { Colitis }\end{array}$ & CT scan & $\begin{array}{l}\text { Resection of pulmonary nodule, } \\
\text { lobectomy }\end{array}$ & $\begin{array}{l}\text { Relapse of } \\
\text { TB }\end{array}$ \\
\hline 2 & $\begin{array}{l}\text { Choi Hun } \\
\text { et al. [8] }\end{array}$ & $46 / \mathrm{F}$ & Abdominal pain & $\begin{array}{l}\text { Primary } \\
\text { peritoneal } \\
\text { carcinoma } \\
\text { (PPC) }\end{array}$ & CT scan & $\begin{array}{l}\text { Total abdominal hysterectomy } \\
\text { (TAH), Bilateral } \\
\text { salpingoophorectomy (BSO), } \\
\text { Omentectomy, Laparotomy }\end{array}$ & Satisfactory \\
\hline 3 & $\begin{array}{l}\text { Choi Hun } \\
\text { et al. [8] }\end{array}$ & 64/F & Abdominal pain & PPC & CT scan & Peritoneal biopsy & Satisfactory \\
\hline 4 & $\begin{array}{l}\text { Choi Hun } \\
\text { et al. [8] }\end{array}$ & $28 / F$ & $\begin{array}{l}\text { Abdominal pain, } \\
\text { Abdominal } \\
\text { distention, Fever }\end{array}$ & PPC & CT scan & Peritoneal biopsy & Satisfactory \\
\hline 5 & $\begin{array}{l}\text { Choi Hun } \\
\text { et al. [8] }\end{array}$ & 40/F & $\begin{array}{l}\text { Abdominal pain, } \\
\text { Fever, } \\
\text { Constipation }\end{array}$ & N/A & CT scan & Peritoneal biopsy & Satisfactory \\
\hline & Choi Hun & & & & & & \\
\hline
\end{tabular}




\section{Cureus}

et al. [8]

33/F

distension

PPC

CT scan

Peritoneal biopsy

Satisfactory

7 Choi Hun

Abdominal pain,

et al. [8] dyspnea

N/A

CT scan

Laparotomy, Mesentery and

omental biopsy

Satisfactory

8 Choi Hun 66/F

Abdominal

distension

N/A

CT scan

Peritoneal biopsy

Satisfactory

Peritoneal biopsy, Unilateral

salpingoophorectomy,

Laparotomy

Satisfactory et al. [8]

23/F

Menorrhagia

Ovarian tumor CT scan

Abdominal

10

Choi Hun 69/F

distension,

Dyspnea

PPC

CT scan

BSO, Peritoneal biopsy,

Laparotomy

Satisfactory

11

Choi Hun

et al. [8] 69/F

Abdominal

PPC

CT scan

Peritoneal biopsy

Satisfactory

Choi Hun

12 et al. [8]

Abdominal pain

N/A

CT scan

Peritoneal biopsy

Satisfactory

Abdominal pain,

Choi Hun $62 / F$

Abdominal

PPC

CT scan

BSO, Omental biopsy,

Laparotomy

Satisfactory

distension

14 Choi Hun 38/F

et al. [8] distension

N/A

CT scan

Peritoneal biopsy

Satisfactory

Abdominal

15

Choi Hun 23/F distension,

et al. [8]

N/A

CT scan

Omental biopsy

Satisfactory

Abdominal pain

Abdominal pain,

Choi Hun

et al. [8]

48/F

Abdominal

PPC

CT scan

Peritoneal biopsy

Satisfactory

distension

17 $41 / F$

Abdominal

et al. [8]

distension

PPC

CT scan

TAH, BSO, Laparotomy

Satisfactory

18

Choi Hun et al. [8]

Fever, Peritonitis

N/A

CT scan

Laparotomy, adhesiolysis, biopsy

Satisfactory

Abdominal

19 Choi Hun 36/F distension,

Abdominal pain,

Ovarian

CT scan

Peritoneal biopsy

Satisfactory

Fever

$20 \begin{aligned} & \text { Choi Hun } \\ & \text { et al. [8] }\end{aligned}$

Abdominal

distension

PPC

CT scan

Omental biopsy

Satisfactory

Abdominal pain,

21 et al. [8] 38/F

Abdominal

PPC

CT scan

Laparotomy, Salpingectomy, distension 


\section{Cureus}

\section{TABLE 1: Characteristics of previously reported cases of mesenteric tuberculous lymphadenitis}

TB: Tuberculosis; CT: Computed tomography; PPC: Primary peritoneal carcinoma; TAH: Total abdominal hysterectomy; BSO: Bilateral salpingoophorectomy.

Although there is no age limit for this disease, there are cases of TL seen in infants as well as those above 60 years of age. A study performed in Chandigarh revealed that TB is more commonly seen in younger age groups (10-30 years) [3]. Another study revealed that the highest incidence of TL in the United Kingdom and United States is 25-50 year age-group [910]. The higher number of cases have been reported in females with the male-to-female ratio of 1:1.2 in a study performed by Dandapat et al. and $1: 1.3$ in a study by Subrahmanyam $[4,11]$. It is proposed that probably women are more conscious of their physical appearance and have a lower nutritional status relative to males in a male-dominated society [1].

There are multiple modes of presentation of the disease, the most common of which are the systemic symptoms of malaise and weight loss [3]. A study conducted by Patel et al. noted weight loss in about $77 \%$ and fever in $73 \%$ of the cases [12]. While in another study by Dandapat et al., it was observed that weight loss was seen in $85 \%$ and fever in $40 \%$ of the patients [ 4 ]. The primary system affected by TB is the bronchopulmonary apparatus, with the head and neck commonly being secondary; therefore, symptoms related to these organs are also noted when they're involved [6]. An abscess or a discharging sinus tract may be another manifestation of disease in patients with TL [13].

The diagnosis of TB can prove to be tricky in cases with extrapulmonary involvement, but three features can help ascertain the diagnosis of TL, they are a multiplicity, matting, and caseation [14]. FNAC is a very popular diagnostic tool for the assessment of cervical swellings. In developing countries where $\mathrm{TB}$ is more common than other granulomatous conditions, the presence of granulomatous features on FNAC is highly suggestive of TB [15]. The diagnosis is further strengthened by observing the Mantoux test and erythrocyte sedimentation rate (ESR), thus eliminating the need for excisional biopsy in most of these patients [3].

Before the advent of chemotherapy, the major mode of treatment of TL was surgical excision of the involved lymph nodes [16]. When chemotherapy for TB was introduced in the 1950s, antiTB chemotherapy for 12 to 24 months was given after excision of all the involved lymph nodes as an effective means of treatment [17]. A study by Cambell et al. revealed that a daily sixmonth chemotherapy regimen has proven to be successful for TL [18]. Studies by Patel et al. and Yuen et al. also confirmed that all the patients could be successfully treated with a short course of six-month chemotherapy with a very rare need for surgical intervention $[12,19]$.

\section{Conclusions}

Extrapulmonary TB, although not as common as pulmonary TB, does exist in the United States so, an inquiry about the country of origin and travel history in a patient with isolated cervical or diffuse lymphadenopathy could help narrow down the differential diagnoses. Endoscopic ultrasound, fine needle aspiration, and fine needle biopsy are useful tools for the diagnosis of TL, especially if the abdominal lymph nodes are the most easily accessible. The chemotherapeutic approach is effective in most patients and surgical intervention can be avoided. 


\section{Additional Information \\ Disclosures}

Conflicts of interest: In compliance with the ICMJE uniform disclosure form, all authors declare the following: Payment/services info: All authors have declared that no financial support was received from any organization for the submitted work. Financial relationships: All authors have declared that they have no financial relationships at present or within the previous three years with any organizations that might have an interest in the submitted work. Other relationships: All authors have declared that there are no other relationships or activities that could appear to have influenced the submitted work.

\section{References}

1. Centers for Disease Control and Prevention. (2018). Accessed: October 22, 2018: https://www.cdc.gov/tb/default.htm.

2. Daniel TM: The history of tuberculosis. Respir Med. 2006, 100:1862-70. 10.1016/j.rmed.2006.08.006

3. Inayat F, Jafar MS, Ali NS, Hussain Q, Hurairah A: Enigma of extrapulmonary tuberculosis: where do we stand?. Cureus. 2017, 9:e1554. 10.7759/cureus.1554

4. Dandapat MC, Mishra BM, Dash SP, Kar PK: Peripheral lymph node tuberculosis: a review of 80 cases. Br J Surg. 1990, 77:911-912. 10.1002/bjs.1800770823

5. Hegde S, Rithesh KB, Baroudi K, Umar D: Tuberculous lymphadenitis: early diagnosis and intervention. J Int Oral Health. 2014, 6:96-98.

6. Mohapatra PR, Janmeja AK: Tuberculous lymphadenitis. J Assoc Physicians India. 2009, 57:585-90.

7. Kraft A, Kreuter M, Herth FJ, Wiebel M: Rezidivierender pulmonaler Rundherd bei Colitis ulcerosa. Dtsch Med Wochenschr. 2009, 134:511-4. 10.1055/s-0029-1208077

8. Choi CH, Kim CJ, Lee YY, et al.: Peritoneal tuberculosis: a retrospective review of 20 cases and comparison with primary peritoneal carcinoma. Int J Gynecol Cancer. 2010, 20:798-803. 10.1111/IGC.0b013e3181e23c8f

9. Alvarez S, MeCabe WR: Extrapulmonary tuberculosis revisited: a review of experience at Boston city and other hospitals. Medicine. 1984, 63:25-53.

10. Monie RDH, Hunter AM, Rocchiccioli KMS, et al.: Management of extra-pulmonary tuberculosis (excluding miliary and meningeal) in South and West Wales (1976-8). Br Med J. 1982, 285:415-418. 10.1136/bmj.285.6339.415

11. Subrahmanyam M: Role of surgery and chemotherapy for peripheral lymph node tuberculosis . Br J Surg. 1993, 80:1547-1548. 10.1002/bjs.1800801218

12. Patel RV, Mehta RT: Short term chemotherapy in tuberculous lymphadenitis. Indian J Surg. 1987, 49:336-341.

13. Cheung WL, Ng A: Tuberculous cervical abscess: comparing the results of total excision against simple incision and drainage. Br J Surg. 1988, 75:563-564. 10.1002/bjs.1800750620

14. Rao KN, Desa AE: Tuberculosis of lymph glands. Textbook of Tuberculosis. Rao KN (ed): Vikas Publishing House, New Delhi; 1981. 476:481.

15. Lau SK, Wei WI, Hsu C, Engzell UCG: Efficacy of fine needle aspiration cytology in the diagnosis of tuberculous cervical lymphadenopathy. J Laryngol Otol. 1990, 104:24-27. 10.1017/S0022215100111697

16. Dowd CN: The surgical treatment of tubercular cervical lymph nodes . Ann Surg. 1905, 42:4974.

17. Byrd RB, Bopp KR, Gracey DR, Puritz EM: The role of surgery in tuberculous lymphadenitis in adults. Am Rev Respir Dis. 1971, 103:816-820.

18. Cambell IA, Ormerod LP, Friend JAR, Jenkins PA, Prescott RJ: Six month versus nine months chemotherapy for tuberculosis of lymph nodes: final result. Respir Med. 1993, 87:621-623. 10.1016/S0954-6111(05)80265-3

19. Yuen APW, Wong SHW, Tam CM, Chan SL, Wei WI, Lau SK: Prospective randomized study of thrice weekly six-month and nine-month chemotherapy for cervical tuberculous lymphadenopathy. Otolaryngol Head Neck Surg. 1997, 116:189-192. 